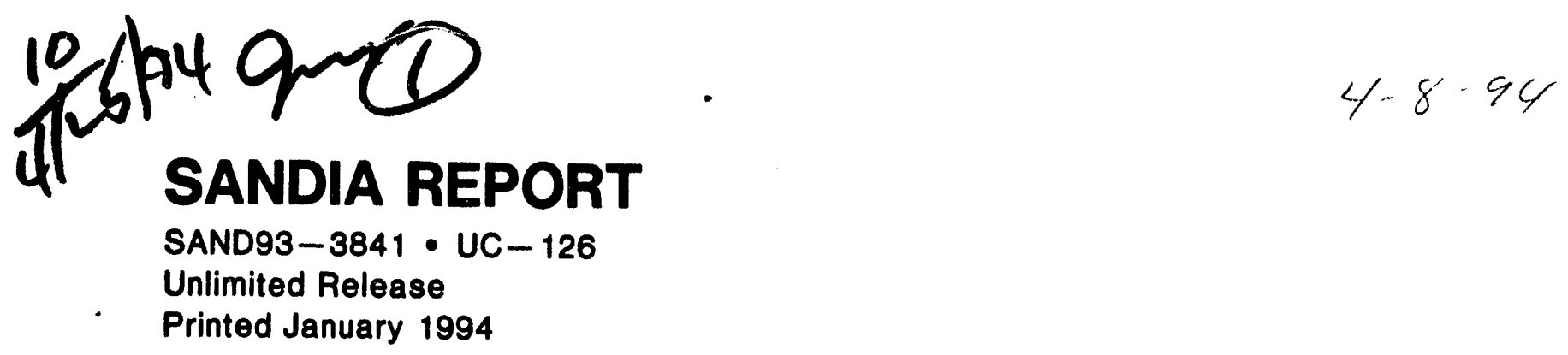

\title{
A User's Manual for the Computer Code HORSMIC
}

\author{
A. J. Russo
}

Propared by

8andia National Laboratorios

Albuquorque, Now Moxlco 87185 and Livermore, Callfornia 94550

for the United States Department of Enorgy

under Contract DE-ACO4-OAAL8S000 
Issued by Sandia National Laboratories, operated for the United States Department of Energy by Sandia Corporation.

NOTICE: This report was prepared as an account of work sponsored by an agency of the United States Government. Neither the United States Government nor any agency thereof, nor any of their employees, nor any of their contractors, subcontractors, or their employees, makes any warranty, express or implied, or assumes any legal liability or responsibility for the accuracy, completeness, or usefulness of any information, apparatus, product, or process disclosed, or represents that its use would not infringe privately owned rights. Reference herein to any specific commercial product, process, or service by trade name, trademark, manufacturer, or otherwise, does not necessarily constitute or imply its endorsement, recommendation, or favoring by the United States Government, any agency thereof or any of their contractors or subcontractors. The views and opinions expressed herein do not necessarily state or reflect those of the United States Government, any agency thereof or any of their contractors.

Printed in the United States of America. This report has been reproduced directly from the best available copy.

Available to DOE and DOE contractors from Office of Scientific and Technical Information PO Box 62

Oak Ridge, TN 37831

Prices available from (615) 576-8401, FTS 626-8401

Available to the public from

National Technical Information Service

US Department of Commerce

5285 Port Royal Rd

Springfield, VA 22161

NTIS price codes

Printed copy: A03

Microfiche copy: A01 
SAND93-3841

Unlimited Release

Printed January, 1994
Distribution

Category UC-126

\title{
A User's Manual for the Computer Code HORSMIC ${ }^{1}$
}

\author{
A. J. Russo \\ Department 1511 \\ Sandia National Laboratories \\ Albuquerque, New Mexico 87185
}

\begin{abstract}
The code HORSMIC was written to solve the problem of calculating the shape of hydrocarbon (gas or liquid) storage caverns formed by solution mining in bedded salt formations. In the past many storage caverns have been formed by vertically drilling into salt dome formations and solution mining largeaspect-ratio, vertically-axisymmetric caverns. This approach is generally not satisfactory for shallow salt beds because it would result in geomechanically-unstable, pancake-shaped caverns. In order to produce a high aspect ratio cavern in the horizontal direction a more complicated strategy must be employed. This report describes one such strategy, and documents the use of the computer model HORSMIC which can be used to estimate the shape of the cavern produced by a prescribed leaching schedule. Multiple trials can then be used to investigate the effects of various pipe hole configurations in order to optixuize over the cavern shape.
\end{abstract}

1. Work performed under a Funds-in-Agreement with Tejas Power Company 


\section{Acknowledgment}

The author wishes to acknowledge the contribution of the Underground Storage Technology Department in the definition of the problem and the review of the results. In particular the helpful discussions and provision of data by P. S. Kuhlman and J. K. Linn are appreciated. 


\section{CONTENTS}

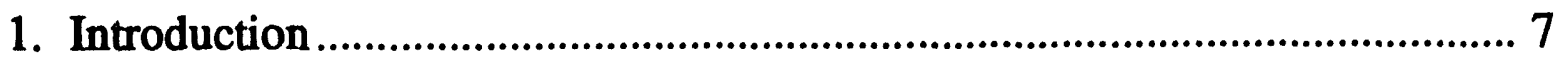

2. Model ......................................................... 7

A sketch of the model solution mining-geometry. ...........................................8

Schematic of perforated pipe flow model. .................................................

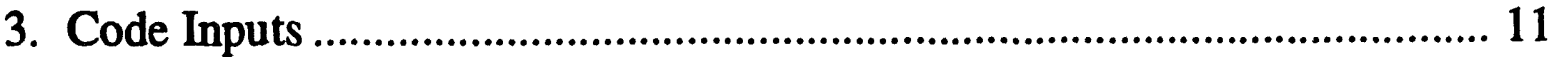

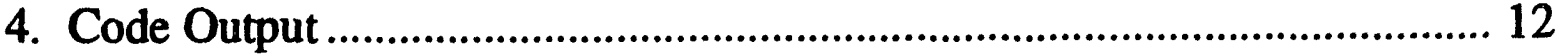

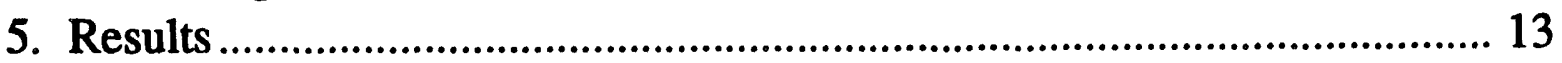

Cavern shape calculated with the horizontal solution code HORSMIC...... 13

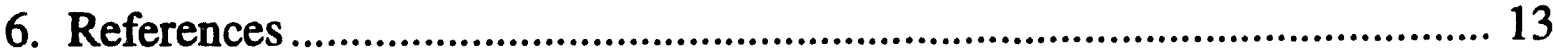

7. Appendix A: Sample Input Data Files for HORSMIC Code........................15

8. Appendix B: Sample Output Data ...............................................................16 


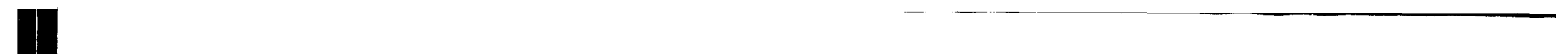




\section{Introduction}

The use of solution mining to generate underground storage space for large quantities of hydrocarbon products has proven to be economical in the past. One of the largest of such enterprises is the storage of hundreds of millions of barrels of oil in solution-mined salt dome caverns by the U.S. Strategic Petroleum Reserve. These caverns were formed by vertically drilling into the salt domes and injecting low salinity water into the dome through inlet and outlet pipe strings which were periodically positioned to shape the dome to desired (high length-to-diameter aspect ratio) specifications. Because the cavern brine tends to stratify, the lowest salinity water accumulates near the top of the cavern and would quickly dissolve the cavern roof till it reached a porous caprock, if it were permitted to make contact with the roof. To prevent contact, a blanket of lighter-than-water material (oil) is injected and floats at the top of the cavern. Several computer models have been used to guide the solution mining operations and to predict the shape and volume of the cavern space. [1,2]. These models make use of the axisymmetric nature of the above mentioned mining process, and the fact that the brine stratifies vertically, to reduce the problem of estimating the dissolution rate to a quasi-one-dimensional problem.

Because the number of salt domes is limited, and their location is not always ideal for storage, there is interest in using bedded salt as a storage medium. Bedded salt exists in deep layers that are a few feet to hundreds of feet thick and are almost horizontal in orientation. It would be possible to generate storage space in these beds by vertical drilling and leaching, as in the dome salt case, however the resultant pancake-shaped caverns would be geomechanically unstable because of the low aspect ratio. To produce a high aspect-ratio, cylindrical cavern in bedded salt therefore requires that the long axis of the cavern lie in the plane of the salt bed. Such a cavern would probably not be axisymmetric and would require a quasi-two-dimensional, or higher, approach to modeling its formation and final shape. There is much less experience in trying to produce such caverns, and the HORSMIC code is intended as a modeling aid to guide the solution mining operation for that case.

\section{Model}

There are a number of possible approaches to leaching a nearly horizontal cavern in a salt bed. The approach that is modeled in HORSMIC is illustrated in Figure 1. A hole is slant-drilled from the surface into a salt bed such that the drill direction proceeds in the plane of the bed and has a downward component. That is, if the bed has a positive downward dip angle of $\varphi$, the drill direction will terminate with a dip angle slightly greater than or equal to $\varphi$. A second hole is drilled vertically from the surface to intersect the first hole at its terminus. The region near the intersection of these two holes will be solution mined to insure a connection between the two holes. A pipe string which is perforated with $\mathrm{n}$ holes per section is inserted in the first hole and positioned in the region of the salt bed where the cavern is to be mined. Water is injected into the perforated pipe string, the end of which is blocked so that the flow exits through the perforated holes and flows along the outside of the pipe to the vertical outlet hole. The portion of the inlet pipe which is not perforated is enclosed in a larger diameter pipe so that as the cavern is formed, a blanket gas or liquid can be injected through the annulus to limit the height of the cavern near the inlet end of the injection string. The diameter of the holes in the inlet pipe string will generally decrease with distance towards the outlet. The tailoring of the hole sizes is one of the factors that will determine the final cavern shape. The amount of salt dissolved depends on the amount of solvent (water) to which it is exposed, the salinity of that solvent, and the flow velocity of the solvent past the eroding cavern walls. The maximum solvent flow rate will occur at the outlet end of the perforated string but the minimum salinity will occur near the inlet end of the 
string. The goal, therefore, is to adjust the hole sizes so that the cavern shape is approximately uniform over the entire length of the cavern. This is accomplished by iterative calculations with different hole sizes to determine the hole pattern that produces the most desirable shape.

Horizontal Solution Mining

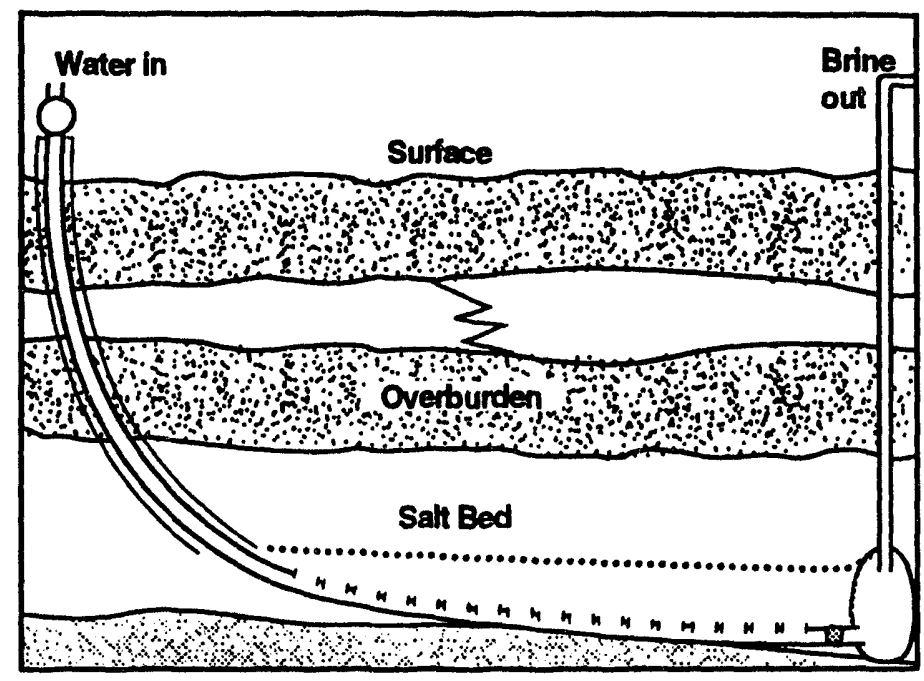

Figure 1. A sketch of the model solution mining geometry.

A schematic of the flow model geometry assumed for the riser termination is shown in Figure 2. A series of holes with variable diameter, $d_{i}$, and separated by a lengthwise distance, $\mathrm{L}$, are drilled through the wall of the inlet pipe (Diameter $D$ and wall thickness $w$ ).

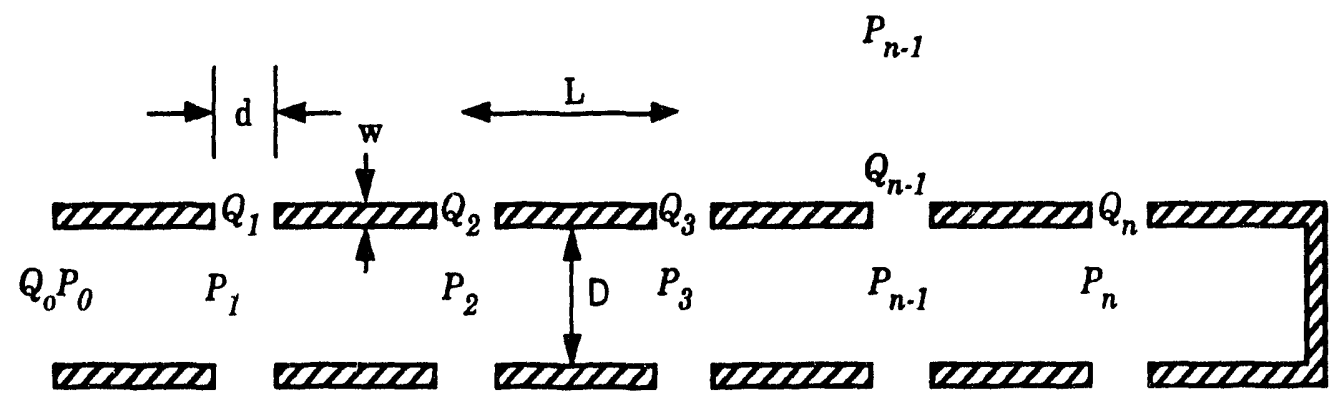

Figure 2. Schematic of perforated pipe flow model.

The inlet pipe is completely blocked at the end. Although only two holes are shown in the figure at 
each axial location, the code permits any number of holes, to be considered.

For steady incompressible flow, Bernoulli's equation may be written as

$$
\frac{v_{a}^{2}}{2}+\frac{P_{a}}{\rho}=\frac{v_{b}^{2}}{2}+\frac{P_{b}}{\rho}+h_{f}
$$

where $v$ is the velocity, $\mathbf{P}$ is the pressure, $\rho$ is the fluid density, and $h_{f}$ is the frictional loss in the pipe. The subscripts $a$ and $b$ refer to any two adjacent sections in the pipe.

The frictional head loss, $h_{f}$, is given by the Darcy-Weisbach equation

$$
h_{f}=f\left\{\frac{L}{D} \frac{v^{2}}{2}\right\}
$$

where the friction factor, $f$, is taken to be 64/Re for Reynold's number, Re, less than 5000 and $f=\frac{0.316}{R e^{0.25}}$ for $\operatorname{Re}>5000$ when the flow is turbulent. $L$ is the length of the tube section and $D$ is its diameter. Since the end of the pipe is plugged, mass conservation requires that the individual flow rates satisfy the constraint

$$
Q_{1}+Q_{2}+Q_{3}+\ldots+Q_{n-1}+Q_{n}=Q_{o}
$$

Combining Eq. 1 and 2, and neglecting the inlet radial velocity, the exit flow rate from each section, assuming the pressure outside the pipe to be independent of position, can be shown to be

$$
Q_{i}=N\left[\frac{1}{1+f \frac{w}{d_{i}}}\right]^{1 / 2} \pi \frac{d_{i}^{2}}{4}\left[\frac{2\left(\Delta P_{i}\right)}{\rho}\right]^{1 / 2}
$$

where $N$ is the number of holes per section, $w$ is the wall thickness of the pipe, $d$ is the orifice diameter, $\Delta P_{i}$ is the pressure change across the pipe wall, and the friction factor, $f$, is evaluated at the flow rate for each exit hole.

From Eq. 1 and 2, the pressure in the pipe at each station, $i$, is given recursively by the expression

$$
P_{i}=P_{i-1}-f \frac{\rho}{2} \frac{L}{D}\left(\frac{Q_{o}-Q_{1}-Q_{2}-\ldots-Q_{i}}{\left(\pi D^{2}\right) / 4}\right)^{2}
$$


Equations 3-5 are solved for the unknown variables $P_{0}, P_{i}$, and $Q_{i}$ for $1 \leq i \leq n$.

This calculation is carried out in a subroutine that is called by a minimizing function which varies the orifice diameters, $d_{i}$, to meet a user-specified criteria. For example, the quantity

$f_{n}=v_{\max }+\sum_{1}^{N}\left|Q_{i}-Q_{i} F^{i-1}\right|$ can be minimized so that the flow out of each orifice decreases by

the factor $F$ and the flow velocity is minimized.

For the region outside the perforated pipe but inside the salt cavity, an equation for the specific gravity of the moving solution may be written as,

$$
\begin{aligned}
C_{i}^{n+1}= & F S G\left(\left[C_{i}^{n} V_{i} W\left(C_{i}^{n}\right)+C_{i-1}^{n} v_{i-1} A_{i-1} \Delta t W\left(C_{i-1}^{n}\right)-C_{i}^{n} v_{i} A_{i} \Delta t W\left(C_{i}^{n}\right)\right.\right. \\
& \left.\left.+A_{i} \Delta z \Delta t\left(\rho_{s} \rho_{w}^{-1}\right)+Q_{i} \Delta t C_{i n} W\left(C_{i n}\right)\right] /\left(C_{i}^{n+1}\left(V_{i}+A_{i} \Delta z \Delta t\right)\right)\right)
\end{aligned}
$$

where $F S G(w)$ is a function that converts the weight percent of salt $w$ to a specific gravity. Its inverse function is $W$. The other variables are; $C_{k}^{n}$, the specific gravity of the solution at the $i$-th mesh point and n-th time step; $V_{i}$, the volume of the $i$-th mesh division and $A_{i}$, its area; $v_{i}$, the bulk fluid velocity in the $\mathrm{i}$-th mesh division; $\Delta z$, the length of a mesh increment in the $\mathrm{z}$ direction (along the pipe); and $\Delta t$, the time step increment. A dot over a quantity indicates the time derivative. All quantities, except $C^{n+1}$, are evaluated at the $n$-th time step. This equation makes use of the assumption that in any region of the dissolving salt the fluid salinity may be characterized by a single parameter in the bulk flow. That is, it is assumed that rapid mixing occurs outside the boundary layer due to turbulence caused by the injected water, convective cells generated at the dissolving salt boundary layer, and flow along the axial direction of the cavern.

When a vertical salt surface is exposed to unsaturated brine, a negatively-buoyant dissolution boundary layer is formed next to the surface. Application of momentum integral analysis to this boundary layer and a series of verification experiments by Durie and Jessen $[3,4]$ showed that when the peakdownward velocity of this boundary layer was large compared to the edge or bulk density of the brine, the dissolution rate at a given temperature varied only with the bulk concentration of the brine and the distance along the boundary layer. Their experiments showed that the transition to turbulence occurred in very small lengths (typically millimeters) and that by analogy with turbulent heat transfer by natural convection on long vertical surfaces, the distance dependence of the dissolution rate could be neglected.

The salt recession rate, $d r / d t$, of a large vertical wall of salt dissolving under the influence of natural convection has been correlated as a function of only the bulk fluid specific gravity, $C$, at temperatures near $75^{\circ} F[1]$.

$$
\begin{gathered}
\frac{d r}{d t}(f t / h r)=45.654996 C^{4}-232.2931 C^{3}+469.5247 C^{2} \\
-470.37554 C+232.73686-45.203241 / C
\end{gathered}
$$

The recession rate varies with wall angle, $\theta$, measured from the vertical, so that $\theta=90^{\circ}$ is an up- 
ward facing surface and $\theta=-90^{\circ}$ is a downward facing surface, according to:

$$
\left.\frac{d r}{d t}\right|_{\theta \geq 0}=\left.\frac{d r}{d t}\right|_{\theta=0} \sqrt{(\cos \theta)}
$$

Eq. 8

$$
\left.\frac{d r}{d t}\right|_{\theta<0}=\left.\frac{d r}{d t}\right|_{\theta=0}\left\{1+0.22\left[1-\sqrt[3]{\frac{\theta+45^{\circ}}{45^{\circ}}}\right]\right\}
$$

\section{Code Inputs}

The following quantities are required as input to operate the code. Each of the values for these quantities are to be listed in the given order, in free format, in an input data fils called DATA. Currently only the English (ft-lb-s) set of units are used except as indicated. The first record consists of a group of integers that define the type of calculation to be performed for that particular data set. The values needed are:

NDIV is the number of axial divisions to be used in the calculation. The number of mesh points used, $\mathrm{N}$, is equal to NDIV+1. N should not exceed the dimension NDM which is currently set to 100 .

NHOLPS is the number of holes per section for solvent flow.

IPRINT is the number of time steps skipped between printouts of shape and leaching concentrations. Each time step has a maximum value of DT hours (see following parameters).

IDATA is currently a dummy variable which should be set to 0 . If set to 1 a set of data must be provided to subroutine DATA to define the initial cavern shape.

IRPT provides information to the code as to whether this is the first data set submitted for the current batch calculation. If IRPT is 0 , that indicates it is the first data set. If IRPT is 1 , then it should be a continuation set.

IRST provides information to the code as to whether the current batch calculation is a continuation from a previous batch calculation. A value of 0 means it is NOT, and a value of 1 indicates that it IS.

IVOL is a desired stop volume, in $\mathrm{kbbl}$, for the calculation. If set to a value less than 1 it is ignored.

The next record contains geometrical and process parameters necessary for the calculation.

YMAX is the initial height (hole diameter) of the cavern.

ALPIP is the perforated length (cavern forming length) of the injection pipe.

$\mathrm{PHI}$ is the pipe dip (from rorizontal) in degrees.

QI is the inlet flow rate of solvent (water) in bbl/day 
RPI is the inside radius of the solvent pipe (inches).

RPO is the outside radius of the solvent pipe (inches).

RCASI is the inside radius of the casing (carrying the blanket material) (inches).

RCASO is the outside radius of the casing (inches).

RHOLO is the initial estimate of the radius of a single perforation in the pipe (inches).

HOLF is the fractional change in hole radius in the direction of flow (e.g. 0.95).

SGI is the specific gravity of the injection water.

SGCF is the initial specific gravity of the cavern fluid.

DT is the maximum time step that will be used in the calculation (hours).

TEND is the maximum (solution) time for which the calculation will run. It may be less if the maximum volume as indicated by IVOL is reached before TEND is reached.

QFIL is the blanket fill rate (assumed to be constant for any one stage (data set)) in standard cubic feet per hour. The code presently is configured for gas blanket fills only.

FINC is the estimated fraction of insolubles (usually anhydrite) in the salt formation to be dissolved.

TEMP is the temperature of the solvent that is injected in degrees $F$.

A sample data set is shown in Appendix A

\section{Code Output}

After printing the input data to the screen as it is read, at every IPRINT time step the code prints values of the stage time, current time step, and total cavern formation time to the screen. This is followed by a table of positions along the pipe with the corresponding values of cavern height, brine specific gravity, flow rate, sectional volume and insoluble level.

Below the table, values of the total cavern volume, (in liquid barrels and gaseous standard cubic feet) the brine outlet flow rate and specific gravity, the remaining insoluble volume and level, the gas blanket level and the volume of brine in the cavern are printed out. A correction factor, obtained by comparing the salt remaining in solution in the cavern with the volume dissolved and removed by brine efflux integrated over time, is used to adjust the cavern specific gravity at each time step. This factor is also printed out, and its proximity to unity is an indicator that a material balance is being maintained. A sample page from the code output is shown in Appendix B.

All of the above information is also written to a file on logical unit 9 so that a record of the entire calculation can be preserved. At the end of a data set, or stage, the volume change for that stage and the leaching efficiency (volume of salt removed per volume of solvent injected) is also written out.

Information needed for continuation of the calculation is written onto logical unit 3 . This file must be available for restarting the calculation (IRST $>0$ ) or for changing stage parameters (IRPT $>0$ ).

Information on the geometrical shape of the cavern is written onto a file on logical unit 12 . These data are in a form suitable for plotting with the commercial plotting code TECPLOT. 


\section{Results}

Figure 3 shows an example of a calculation for a cavern shape performed with HORSMIC. In this calculation it is assumed that the dip angle of the salt bed and string is 5 degrees and the flow rates varied between 100,000 and 150,000 barrels per day. The perforated pipe lies at the lowest portion of the cavern and is covered by a porous insoluble layer through which the injection water flows.

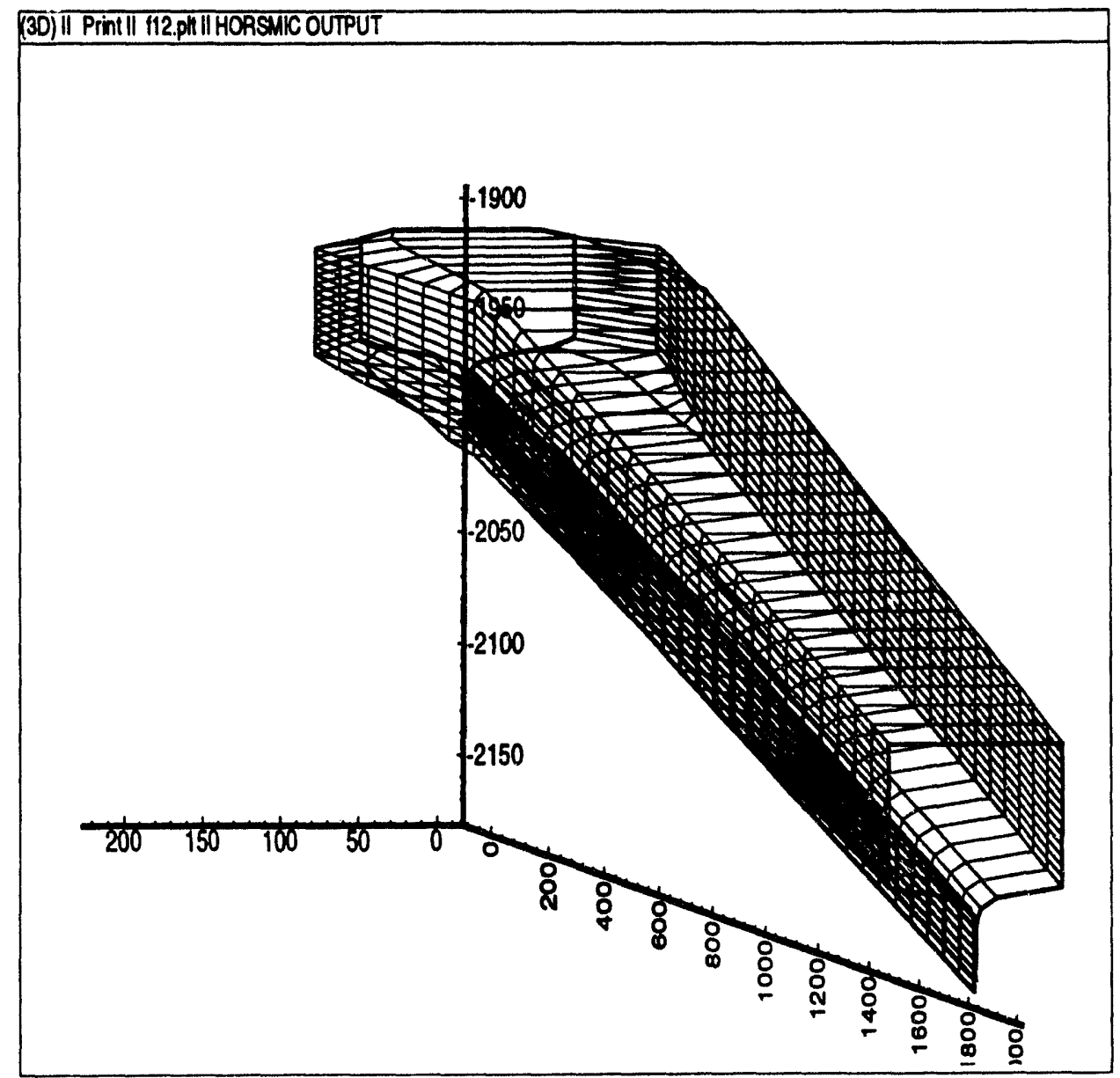

Figure 3. Cavern shape calculated with the horizontal solution code HORSMIC.

\section{References}

1. A. J. Russo, A Users Manual for the Salt Solution Mining Code SANSMIC, Sandia National Laboratories Report SAND83-1150, September 1983. 
2. A. Saberian and A. L. Podio, "A Computer Model for Describing the Development of Solution-Mined Cavities, ${ }^{n}$ In Situ, 1(1), p. 1-36, 1977.

3. R. N. Durie and F. W. Jessen, "The Mechanism of the Dissolution of Salt in the Formation of Underground Salt Cavities." SPE Journal, p. 183, June 1964.

4. R. N. Durie and F. W. Jessen, "The Influence of Surface Features in the Salt Dissolution Process," SPE Journal, p. 275, September 1964. 


\section{Appendix A}

\section{Sample Input Data Files for HORSMIC Code.}

3112240001000

2.02000 .02000 .05 .050000 .08 .010 .012 .013 .0

0.20 .981 .0021 .202 .072 .00 .00 .175 .0

3112240101000

2.02000 .02000 .05 .0100000 .08 .010 .012 .013 .0

0.20 .981 .0021 .202 .0960 .00 .00 .175 .0

3112240101000

2.02000 .02000 .05 .0100000 .08 .010 .012 .013 .0

0.20 .981 .0021 .202 .02000 .05 .00 .175 .0

In the above data set each three-line group represents one stage of solution mining. The first of three stages is limited to 72 hours of inlet flow at $50000 \mathrm{bbl} /$ day. The next two stages lasting 960 and 2000 hours respectively have an inlet flow rate of $100000 \mathrm{bbl} /$ day.

In each stage a cavern volume limit of $1000 \mathrm{kbbl}$ is specified so that if any time the volume reaches this limit the stage will terminate before the specified time limit.

The following data set is similar to the first only the first stage is longer and utilizes a higher flow rate, and the final cavern volume is set at $4000 \mathrm{kbbl}$. This data set was used to generate the cavern shape shown in the results section.

3112240014000

2.02000 .02000 .05 .0150000 .08 .010 .012 .013 .0

0.20 .981 .0021 .202 .0960 .00 .00 .175 .0

3112240104000

2.02000 .02000 .05 .0100000 .08 .010 .012 .013 .0

0.20 .981 .0021 .202 .0960 .00 .00 .175 .0

3112240104000

2.02000 .02000 .05 .0100000 .08 .010 .012 .013 .0

0.20 .981 .0021 .202 .02000 .04 .00 .175 .0 


\section{Appendix B}

\section{Sample Output Data}

TIME $=0.08$ DAYS DT $=2.00$ HOURS START TIME $=326.76$ DAYS

\begin{tabular}{|c|c|c|c|c|c|}
\hline LENGTH & HEIGHT & BRINE S.G. & FLOW RATE & VOL.(BBL) & INS. LEVEL \\
\hline 2000.0 & 105.95 & 1.1432 & 150000.06 & 78852.18 & 39.834 \\
\hline 1935.5 & 106.72 & 1.1427 & 146406.06 & 79983.85 & 40.137 \\
\hline 1871.0 & 107.30 & 1.1422 & 142737.70 & 81091.59 & 40.400 \\
\hline 1806.5 & 107.47 & 1.1417 & 138994.66 & 82030.79 & 40.468 \\
\hline 1741.9 & 107.64 & 1.1413 & 135175.25 & 82968.44 & 40.577 \\
\hline 1677.4 & 107.81 & 1.1408 & 131277.83 & 83924.45 & 40.663 \\
\hline 1612.9 & 107.98 & 1.1403 & 127300.63 & 84906.37 & 40.766 \\
\hline 1548.4 & 108.16 & 1.1398 & 123241.78 & 85917.10 & 40.831 \\
\hline 1483.9 & 108.31 & 1.1394 & 119100.63 & 86950.12 & 40.910 \\
\hline 1419.4 & 108.47 & 1.1390 & 114875.18 & 88005.51 & 40.957 \\
\hline 1354.8 & 108.62 & 1.1385 & 110563.30 & 89088.50 & 41.035 \\
\hline 1290.3 & 108.78 & 1.1381 & 106164.12 & 90214.61 & 41.084 \\
\hline 1225.8 & 108.91 & 1.1377 & 101673.94 & 91629.09 & 41.129 \\
\hline 1161.3 & 109.04 & 1.1373 & 97093.02 & 93034.57 & 41.149 \\
\hline 1096.8 & 109.20 & 1.1369 & 92418.80 & 94389.73 & 41.231 \\
\hline 1032.3 & 109.32 & 1.1366 & 87648.59 & 95761.61 & 41.292 \\
\hline 967.7 & 109.48 & 1.1362 & 82780.89 & 97135.91 & 41.376 \\
\hline 903.2 & 109.61 & 1.1358 & 77814.12 & 98475.88 & 41.423 \\
\hline 838.7 & 109.76 & 1.1354 & 72746.57 & 99825.46 & 41.496 \\
\hline 774.2 & 109.91 & 1.1351 & 67574.89 & 101163.52 & 41.568 \\
\hline 709.7 & 110.04 & 1.1347 & 62297.03 & 102502.27 & 41.612 \\
\hline 645.2 & 110.16 & 1.1343 & 56912.21 & 103855.72 & 41.689 \\
\hline 580.6 & 110.29 & 1.1339 & 51418.05 & 105229.09 & 41.736 \\
\hline 516.1 & 110.41 & 1.1335 & 45810.43 & 106820.72 & 41.763 \\
\hline 451.6 & 110.55 & 1.1330 & 40089.59 & 108379.05 & 41.812 \\
\hline 387.1 & 110.69 & 1.1321 & 34250.98 & 109911.23 & 41.861 \\
\hline 322.6 & 108.43 & 1.1297 & 28294.49 & 110949.91 & 41.833 \\
\hline 258.1 & 102.80 & 1.1280 & 22215.07 & 111390.37 & 41.628 \\
\hline 193.5 & 97.18 & 1.1262 & 16012.20 & 110676.81 & 40.706 \\
\hline 129.0 & 91.55 & 1.1261 & 9681.96 & 105669.37 & 38.908 \\
\hline 64.5 & 85.94 & 1.1450 & 3223.40 & 64152.93 & 34.876 . \\
\hline
\end{tabular}

TOTAL VOLUME $=2924886.8 \mathrm{BBLS}=982273088.0 \mathrm{SCF}$

BRINE OUT $=139796.16 \mathrm{BBLS} / \mathrm{DAY} \quad$ OUTLET SPECIFIC GRAVITY $=1.1432$ VOLUME OF INSOLUBLES $=324876.16 \mathrm{BBLS}$ INSOL LEVEL $=39.83 \mathrm{FT}$ BLANKET LEVEL $=85.93 \mathrm{FT}$ VOL OF INS VENTED $=\quad 0.00 \mathrm{BBLS}$ BRINE VOLUME $=2924862.75 \mathrm{BBLS} \quad \mathrm{CFAC}=0.9999695 \mathrm{XOR}=0.23471$ 


\section{Distribution}

U. S. DOE SPR PMO (9)

900 Commerce Road East

New Orleans, LA 70123

Attn: J. C. Kilroy, FE-443

J. W. Kunkel, FE-4422(3)

L. J. Rousseau, FE-443

J. Culbert, FE-4431

R.E. Meyers, FE-4422

TDCS (2)

U. S. Department of Energy (2)

Strategic Petroleum Reserve

1000 Independence Avenue SW

Washington, D.C. 20585

Attn:

R. Smith

D. Johnson

Tejas Power Corporation

200 Westlake Park Boulevard

Suite 1000

Houston, TX 77079

Attn: H.J. Heneman

Sandia Internal:

\begin{tabular}{lll} 
MS0841 & 1500 & D.J. McClosky \\
MS0827 & 1511 & J.S. Rottler \\
MS0827 & 1511 & A.J. Russo (10) \\
MS0706 & 6113 & J.K. Linn \\
MS0706 & 6113 & P.S. Kuhlman. \\
MS0899 & 7141 & Technical Library \\
MS0619 & 7151 & Tech. Publications \\
MS1119 & $7613-2$ & Document Processing \\
\multicolumn{3}{c}{ for DOE/OSTI (10) } \\
MS9018 & $8523-2$ & Central Technical
\end{tabular}

Files 

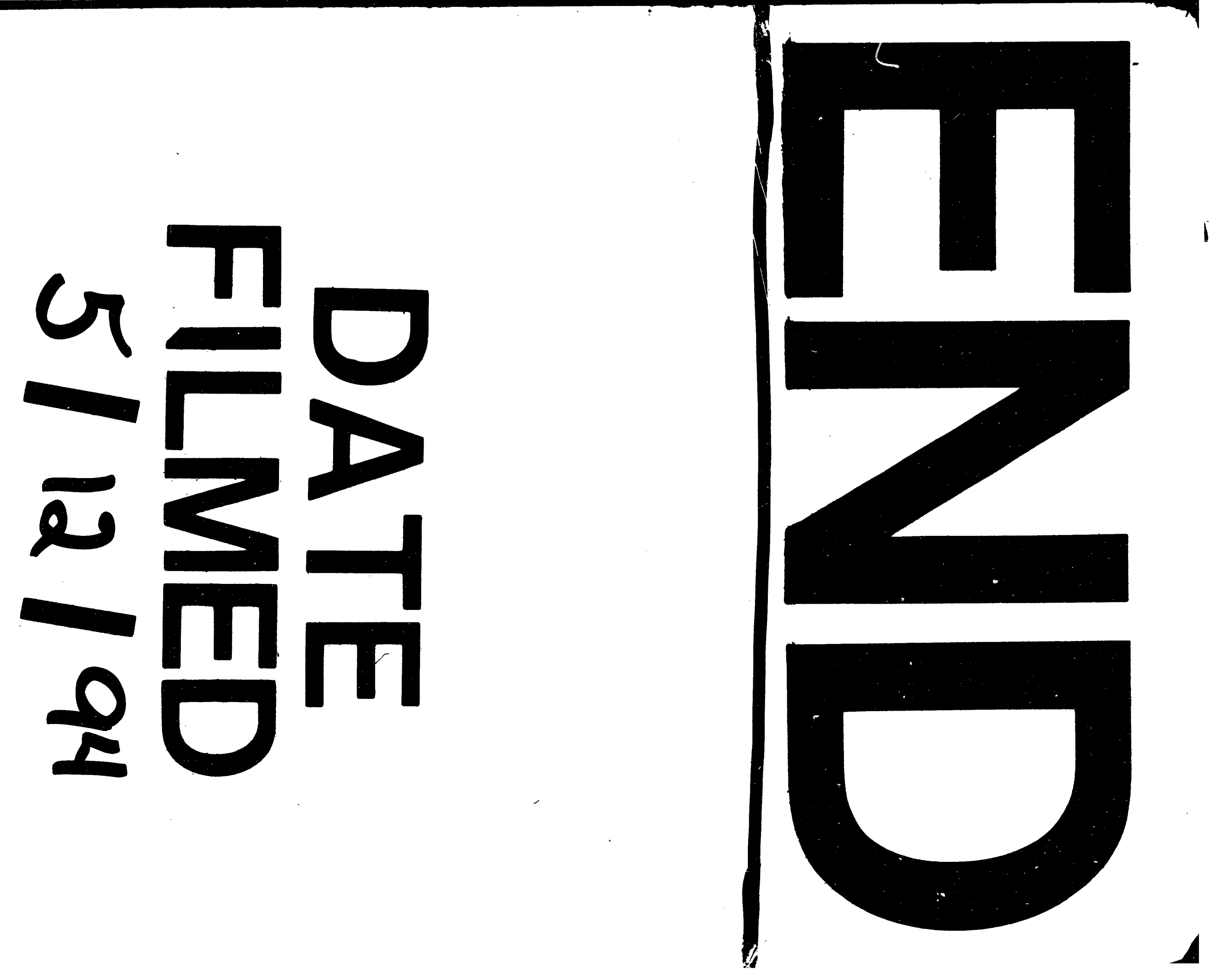
